\title{
Reduction and comparison of compressed air consumption in linear pneumatic motors
}

\author{
Kamil Fojtášek ${ }^{1, a}$, Antonín Dorazil ${ }^{2}$, Dorota Homa $^{3}$ \\ 1, 2, VŠB-Technical University of Ostrava, Faculty of Mechanical Engineering, Department of Hydrodynamics \\ and Hydraulic Equipment, 17. listopadu 15/2172, Ostrava 70833, Czech Republic \\ ${ }^{3}$ Silesian University of Technology, Faculty of Energy and Environmental Engineering, Institute of Power \\ Engineering and Turbomachinery, Konarskiego Street 18, 44100 Gliwice, Poland
}

\begin{abstract}
Pneumatic mechanisms are used in a wide range of industrial applications. For transmission of energy and information in pneumatic mechanism are used compressed air. Production and distribution of compressed air in pneumatic systems leads to considerable losses. This fact causes a relatively low overall efficiency of the pneumatic system. The article will compare the possibilities of reducing compressed air consumption in linear pneumatic motors.
\end{abstract}

\section{Introduction}

Reducing compressed air consumption is a very actual theme. Manufacturers of pneumatic mechanisms are still coming up with new trends in energy savings. Compressed air is a very expensive energy source. It is reported that up to ten times more expensive than electrical energy. Yet, in the various fields of industry, the pneumatic mechanisms have an irreplaceable place. This is primarily due to good safety, cleanliness, high speed of operations and simple automation of operations. In the past, compressed air savings have been sought primarily in its production and distribution. While adhering to the design principles and the correct diagnostics of the system, the broadest area to find suitable solutions to reduce energy consumption is in pneumatic motors and final appliances. The largest share in the production (and hence in the applications) of pneumatic elements has control elements and linear motors. In this paper, the compressed air consumption will be compared for the different energy-saving connections of the pneumatic circuit. The comparison will be made on a relatively simple circuit, with one pneumatic linear motor. Compressed air consumption will be determined on the basis of measured data and theoretical calculations.

\section{Theory}

Compressed air consumption in pneumatic mechanisms can be expressed as a volume of air over the time, which is usually used in non-repeating processes, variable loads, or when using a rotary output member. Another option is expressed in cubic meters, as the volume of compressed air consumed to perform a working operation. This expression is suitable for applications with linear pneumatic motors. In these applications, the motor often performs repeated linear motion with a constant load. In this case, the working operation consists of the piston rod extension and retraction, which can be called one working cycle. In order to ascertain the compressed air consumption as accurately as possible, four different methods were used. The first method is to manually read the compressed air consumption from the flowmeter display. The accuracy of this method is given by the display options of used flowmeter (in our case, to tenths of cubic decimeters). Another method is to compute consumption as a area under the curve of the measured compressed air flowrate data. This method should be the most accurate, the measurement uncertainty is given only by the accuracy of used flowmeter. Theoretical calculation can also be used to determine compressed air consumption in a linear motor. For comparison, formulas from two different sources were used. The first is a classical calculation [1].

$$
Q_{N}=\frac{\pi}{4} \cdot s \cdot n \cdot\left(2 \cdot D^{2}-d^{2}\right) \cdot \frac{p_{a b s}}{p_{N}}\left[m_{N}^{3} \cdot \min ^{-1}\right]
$$

where $s[\mathrm{~m}]$ is the stroke of piston, $n\left[\mathrm{~min}^{-1}\right]$ is the number of cycles per minute, $D[m]$ is diameter of piston, $d[m]$ is diameter of piston rod, $p_{a b s}[\mathrm{~Pa}]$ is absolute pressure and $p_{N}[\mathrm{~Pa}]$ is normal (atmospheric) pressure.

The second formula is from SMC company [2] which does not consider different area on piston and piston rod side. In addition, in calculation is included a coefficient for compensate a thermodynamic losses.

$$
Q_{N}=1.4 \cdot \frac{\pi}{4} \cdot s \cdot n \cdot 2 \cdot D^{2} \cdot \frac{p_{a b s}}{p_{N}}\left[\mathrm{~m}_{N}^{3} \cdot \mathrm{min}^{-1}\right]
$$

\footnotetext{
${ }^{\mathrm{a}}$ Corresponding author: kamil.fojtasek@vsb.cz
} 
where 1.4 is coefficient for compensate a thermodynamic losses, $s[\mathrm{~m}]$ is the stroke of piston, $n\left[\mathrm{~min}^{-1}\right]$ is the number of cycles per minute, 2 is coefficient which includes extension and retraction of piston, $D[\mathrm{~m}]$ is diameter of piston, $d[\mathrm{~m}]$ is diameter of piston rod, $p_{a b s}$ $[\mathrm{Pa}]$ is absolute pressure and $p_{N}[\mathrm{~Pa}]$ is normal (atmospheric) pressure.

To compare the possibilities of reducing compressed air consumption was based on commonly available materials of the leading manufacturers of pneumatic components. The first task is to save compressed air by interruption of air supply if the valve has switched. This connection is mentioned by FESTO [3], it is essentially about use the directional control valve with closed mid position Fig.1.
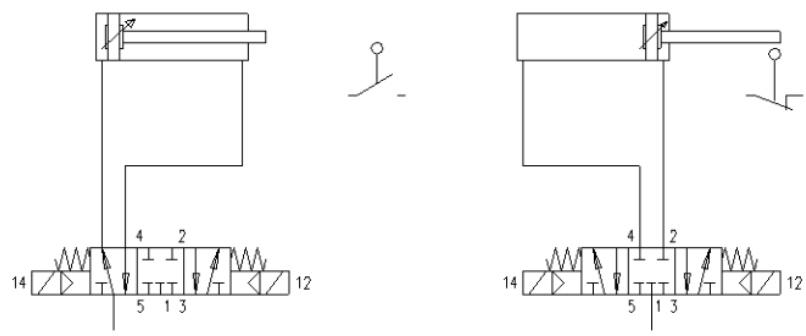

Fig. 1. Interruption of air supply if valve has switched [3]

The next task for air savings is using a pressure regulator, specifically ASR valve from SMC Fig.2. [4]. This combined valve ASR allows speed control by throttling valve during the extension stroke and reducing the pressure in the piston rod chamber during piston rod retracting. Pressure reduction is advantageous in the case where the piston rod retracts unloaded and compressed air only overcomes the friction of the piston and piston rod. Pressure reduction causes energy saving. According to pressure value for rod retraction is possible to save up to $40 \%$ of compressed air per working cycle of the cylinder. More has been described in article [5].
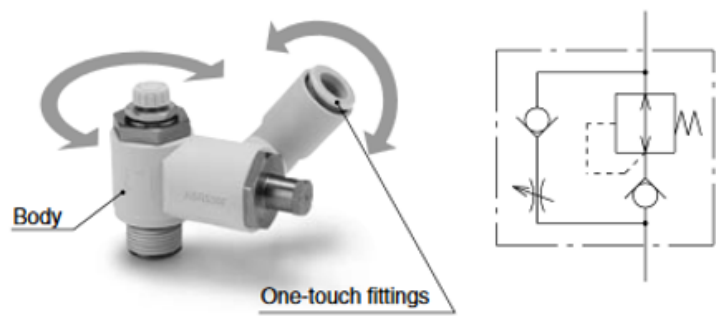

Fig. 2. ASR air saving pressure regulator valve SMC [4]

The next task is utilization of accumulated exhaust air to return stroke of cylinder piston [6]. This solution is more complicated in term of the number of elements, but there is a option up to almost $50 \%$ of compressed air savings in relations to the ration of piston and piston rod diameter and set control pressure in air reservoir. Pneumatic circuits of all solved were slightly modified.

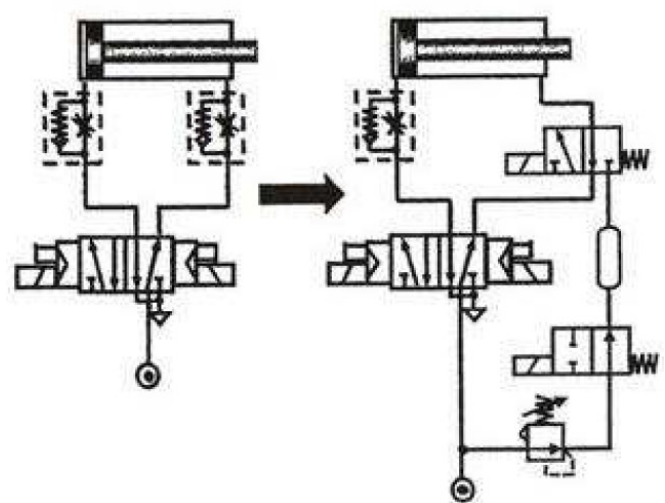

Fig. 3. Utilization of accumulated exhaust air to return stroke of cylinder [6]

\section{Measurement methodology}

First, a basic pneumatic circuit was built, this circuit does not contain any elements to reduce consumption of compressed air. The scheme of this circuit is in Fig.4. The results measured by this circuit serve as a reference measurement and then will be compared with data obtained on circuits with compressed air savings. For all measurements was used a standard pneumatic double acting cylinder 7 (linear motor) SMC C92, with a piston diameter $40 \mathrm{~mm}$, piston rod diameter $16 \mathrm{~mm}$ and stroke $500 \mathrm{~mm}$. Pneumatic motor was loaded with $m=20 \mathrm{~kg}$ of weight and worked with two input pressures $0.3 \mathrm{MPa}$ and $0.4 M P a$. Each measurement was performed for 10 operating cycles (one cycle is double stroke of piston). It was measured input $p_{1}[M P a]$ and output $p_{2}[M P a]$ pressure in pneumatic cylinder by pressure sensors 5,6 , position of piston rod $s[\mathrm{~m}]$ by position sensor 8 and flow rate $Q_{1}\left[\mathrm{dm}^{3} \cdot \mathrm{s}^{-1}\right]$ of compressed air by a flowmeter 2 (which recorded consumption).

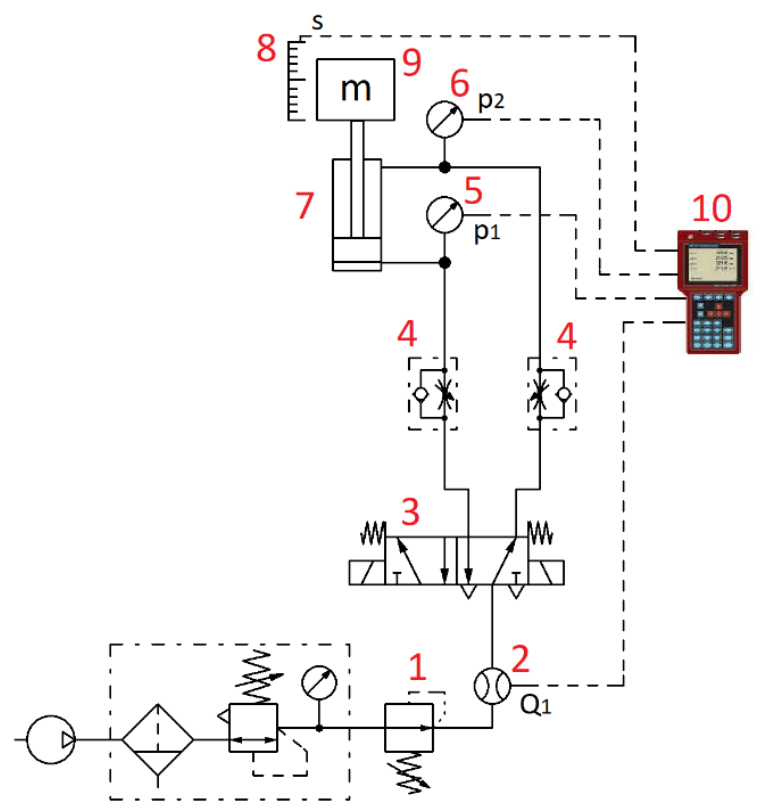

Fig. 4. Scheme of pneumatic circuit for reference measurement 1 -reduction valve, 2 -flow meter, 3 -directional control valve, 4 - throttle and check valve, 5 - pressure $p_{1}$ sensor, $6-$, pressure $p_{2}$ sensor 7 - pneumatic cylinder (linear motor), 8 -position sensor, 9 - mass load, 10 - measuring equipment M5050 
The realization of reference measurement without energy savings is in Fig.5.

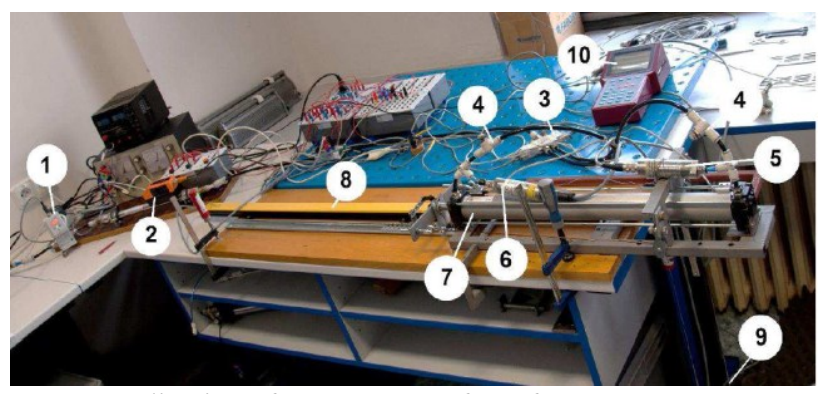

Fig. 5. Realization of measurement for reference measurement 1 -reduction valve, 2 -flow meter, 3 -directional control valve, 4 -throttle and check valve, 5 - pressure $p_{1}$ sensor, 6 -, pressure $p_{2}$ sensor 7 - pneumatic cylinder (linear motor), 8 - position sensor, 9 - mass load, 10 - measuring equipment M5050

The measurement has been recorded separately for extension and retraction of piston rod. For example the measured data are graphically displayed in Fig.6 and Fig.7, for working pressure $0.3 \mathrm{MPa}$. The velocity $v_{1}$ was calculated from the change of position over time.

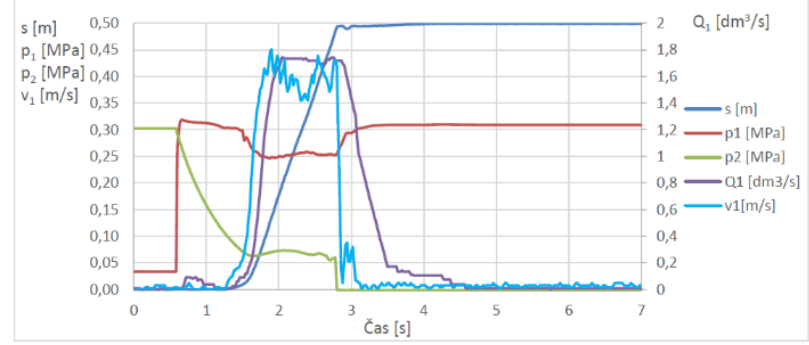

Fig. 6. Graph of measured data for extension of piston rod, for working pressure $0.3 \mathrm{MPa}$

$s$ - position of piston rod, $p_{1}$ - pressure on piston side, $p_{2}-$ pressure on piston rod side, $Q_{1}$ - flow rate, $v_{1}$-velocity of piston rod

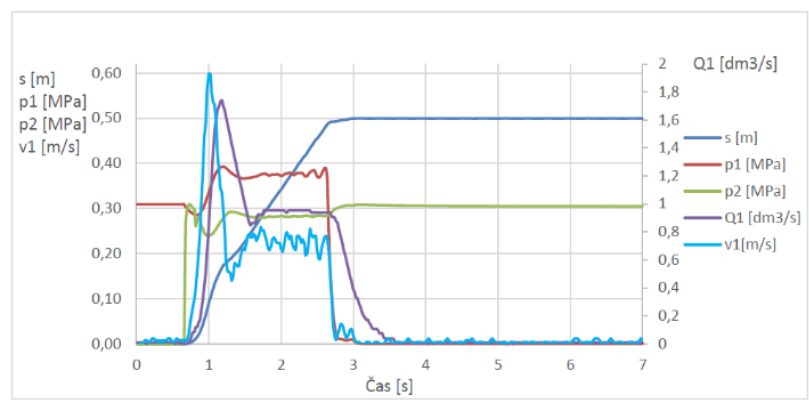

Fig. 7. Graph of measured data for retraction of piston rod, for working pressure $0.3 \mathrm{MPa}$

The consumption of compressed air was determined by the four methods which have been mentioned in the previous chapter. First method is manual reading of the values from the flowmeter display after the first, fifth and tenth working cycles Tab. 1 .

The next method is sum (extension and retraction) of areas under the curve of flow rate from measuring. For calculation was used software MS Excel and graphically is shown in Fig.8. The consumption by this method is $4.821 \mathrm{dm}^{3}$ for working pressure $0.3 \mathrm{MPa}$, and $5.852 \mathrm{dm}^{3}$ for working pressure $0.4 \mathrm{MPa}$.
Tab. 1. Consumption of compressed air by manual reading from flowmeter display

\begin{tabular}{|c|c|c|}
\hline $\begin{array}{c}\text { Number of cycles } \\
{[-]}\end{array}$ & $\begin{array}{c}\text { Reference } \\
\text { measurement for } \\
0.3 \mathrm{MPa} \\
{\left[\mathrm{dm}^{3}\right]}\end{array}$ & $\begin{array}{c}\text { Reference } \\
\text { measurement for } \\
0.4 \mathrm{MPa} \\
{\left[\mathrm{dm}^{3}\right]}\end{array}$ \\
\hline 1 & 5 & 6 \\
\hline 5 & 22.5 & 28 \\
\hline 10 & 45 & 56 \\
\hline $\begin{array}{c}\text { Average } \\
\text { consumption per } \\
\text { one cycle }\end{array}$ & 4.5 & 5.6 \\
\hline
\end{tabular}

The next method is sum (extension and retraction) of areas under the curve of flow rate from measuring. For calculation was used software MS Excel and graphically is shown in Fig.8. The consumption by this method is $4.821 \mathrm{dm}^{3}$ for working pressure $0.3 \mathrm{MPa}$, and $5.852 \mathrm{dm}^{3}$ for working pressure $0.4 \mathrm{MPa}$.
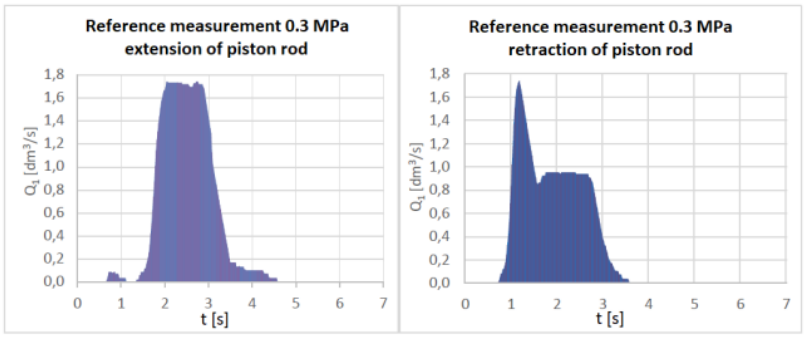

Fig. 8. Graph of sum areas under the flow rate curve, for working pressure $0.3 \mathrm{MPa}$

The next method is calculation from equitation (1) for one working cycle and pressure $0.3 \mathrm{MPa}$.

$$
\begin{aligned}
V_{\text {ref } 0.3}= & \frac{\pi}{4} \cdot 0.5 \cdot 1 \cdot\left(2 \cdot 0.04^{2}-0.016^{2}\right) \cdot \frac{4.01325 \cdot 10^{5}}{1.01325 \cdot 10^{5}} \\
& V_{\text {ref } 0.3}=0.004581 \mathrm{~m}^{3}=4.581 \mathrm{dm}^{3}
\end{aligned}
$$

The last method is using by equitation (2), again for one working cycle and pressure $0.3 \mathrm{MPa}$.

$$
\begin{gathered}
V_{r e f 0.3}^{*}=1.4 \cdot \frac{\pi}{4} \cdot 0.5 \cdot 1 \cdot 2 \cdot 0.04^{2} \cdot \frac{4.01325 \cdot 10^{5}}{1.01325 \cdot 10^{5}} \\
V_{r e f 0.3}^{*}=0.00697 \mathrm{~m}^{3}=6.97 \mathrm{dm}^{3}
\end{gathered}
$$

The comparison of consumption for reference measurement is in Tab.2.

Tab. 2. Comparison of each method to determine consumption of compressed air for reference measurement

\begin{tabular}{|c|c|c|}
\hline Method & $\begin{array}{c}\text { Working } \\
\text { pressure } \\
0.3 \mathrm{MPa} \\
{\left[\mathrm{dm}^{3}\right]}\end{array}$ & $\begin{array}{c}\text { Working } \\
\text { pressure } \\
0.4 \mathrm{MPa} \\
{\left[\mathrm{dm}^{3}\right]}\end{array}$ \\
\hline Flowmeter display & 4.5 & 5.6 \\
\hline Area under the curve & 4.821 & 5.852 \\
\hline Classic formula & 4.581 & 5.722 \\
\hline SMC formula & 6.97 & 8.707 \\
\hline
\end{tabular}

Table 2 clearly shows that the first three methods are differ only slightly, while the SMC calculation is considerably inaccurate. This phenomenon occurred in all measurements.

Now the following is a description of each of the solved tasks for compressed air savings. The measured task for circuit with directional control valve with closed mid position (interruption of air supply) is shown on Fig.9. 




Fig. 9. The scheme of measurement with interruption of air supply

1 -reduction valve, 2 -flow meter, 3-directional control valve, 4 -throttle and check valve, 5 - pressure $p_{1}$ sensor, 6 -, pressure $p_{2}$ sensor 7 - pneumatic cylinder (linear motor), 8 -position sensor, 9 - mass load, 10 - measuring equipment M5050

This task is very similar to reference measurement. The difference is only in directional control valve 3 . When piston rod reached to the end position, than it was switched the directional control valve to the middle position. A part of compressed air with small amount of pressure stay closed between directional control valve and linear motor. The comparison of air consumption for this task is in Tab.3.

Tab. 3. Comparison of each method to determine consumption of compressed air for measurement with interruption of air

\begin{tabular}{|c|c|c|}
\multicolumn{3}{|c|}{ supply } \\
& Working & Working \\
& pressure & pressure \\
& $0.3 \mathrm{MPa}$ & $0.4 \mathrm{MPa}$ \\
& {$\left[\mathrm{dm}^{3}\right]$} & {$\left[\mathrm{dm}^{3}\right]$} \\
\hline Flowmeter display & 4.2 & 5.2 \\
\hline Area under the curve & 4.243 & 5.267 \\
\hline Classic formula & 4.124 & 5.476 \\
\hline SMC formula & 6.623 & 8.362 \\
\hline
\end{tabular}

The scheme of measured task with using a pressure regulator ASR valve is shown in the Fig.10. ASR valve regulated the retraction pressure. Reduction in compressed air consumption is therefore due to a reduction in retraction pressure. This can only be used if the pneumatic motor is not loaded in both directions. The measurement were made for four combinations of working/retraction pressure (0.3/0.1 MPa, 0.3/0.2 MPa, 0.4/0.1 $\mathrm{MPa}$ and 0.4/0.2 $M P a)$. The assumption is that the lower the pressure required for motor backward movement, the greater the savings in compressed air.

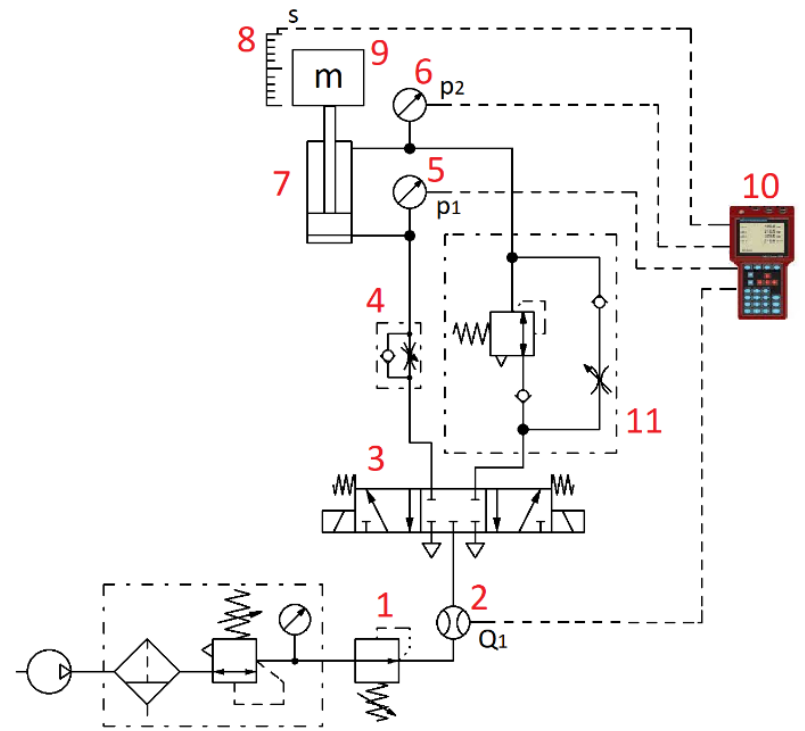

Fig. 10. The scheme of measurement with ASR pressure regulator

1 -reduction valve, 2 -flow meter, 3 -directional control valve, 4-throttle and check valve, 5 - pressure $p_{1}$ sensor, 6 -, pressure $p_{2}$ sensor 7 - pneumatic cylinder (linear motor), 8 -position sensor, 9 - mass load, 10 - measuring equipment M5050, $11-A S R$ pressure regulator Tab.4.

The comparison of air consumption for this task is in

Tab. 4. Comparison of each method to determine consumption of compressed air for measurement with ASR pressure regulator

\begin{tabular}{|c|c|c|c|c|}
\hline & \multicolumn{4}{|c|}{ Working/retracting pressure } \\
\hline Method & $\begin{array}{c}0.3 / 0.1 \\
\mathrm{MPa} \\
{\left[\mathrm{dm}^{3}\right]}\end{array}$ & $\begin{array}{c}0.3 / 0.2 \\
\mathrm{MPa} \\
{\left[\mathrm{dm}^{3}\right]}\end{array}$ & $\begin{array}{c}0.4 / 0.1 \\
\mathrm{MPa} \\
{\left[\mathrm{dm}^{3}\right]}\end{array}$ & $\begin{array}{c}0.4 / 0.2 \\
\mathrm{MPa} \\
{\left[\mathrm{dm}^{3}\right]}\end{array}$ \\
\hline $\begin{array}{c}\text { Flowmeter } \\
\text { display }\end{array}$ & 3.5 & 4 & 4.05 & 4.6 \\
\hline $\begin{array}{c}\text { Area } \\
\text { under the } \\
\text { curve }\end{array}$ & 3.671 & 4.198 & 4.226 & 4.811 \\
\hline $\begin{array}{c}\text { Classic } \\
\text { formula }\end{array}$ & 3.53 & 4.051 & 4.151 & 4.673 \\
\hline $\begin{array}{c}\text { SMC } \\
\text { formula }\end{array}$ & 5.933 & 7.148 & 6.801 & 8.017 \\
\hline
\end{tabular}

The scheme of measured task with using utilization of accumulated exhaust air to return stroke of cylinder piston is shown in Fig.11. In this scheme are two pneumatic operated $3 / 2$ directional control valves 12 and 13 . Directional control valve 13 is controlled by time delay valve with normally closed 11 . To both $3 / 2$ directional control valves is connected air reservoir 14 . For extension of piston rod is switched 5/3 directional control valve 3 to the right position. For retraction of piston rod is switched valve 3 to the left position, valve 12 is switched to left position and reservoir helping with retraction. After a time delay (which is setup on valve 11) is switched valve 13 and reservoir 14 is pressurized again. In this task was made measurement also without any mass load, to confirm that the piston rod is retracting due to accumulated air in reservoir (and not only due to the mass load). The pneumatic circuit worked correctly with the mass load even without the load. 


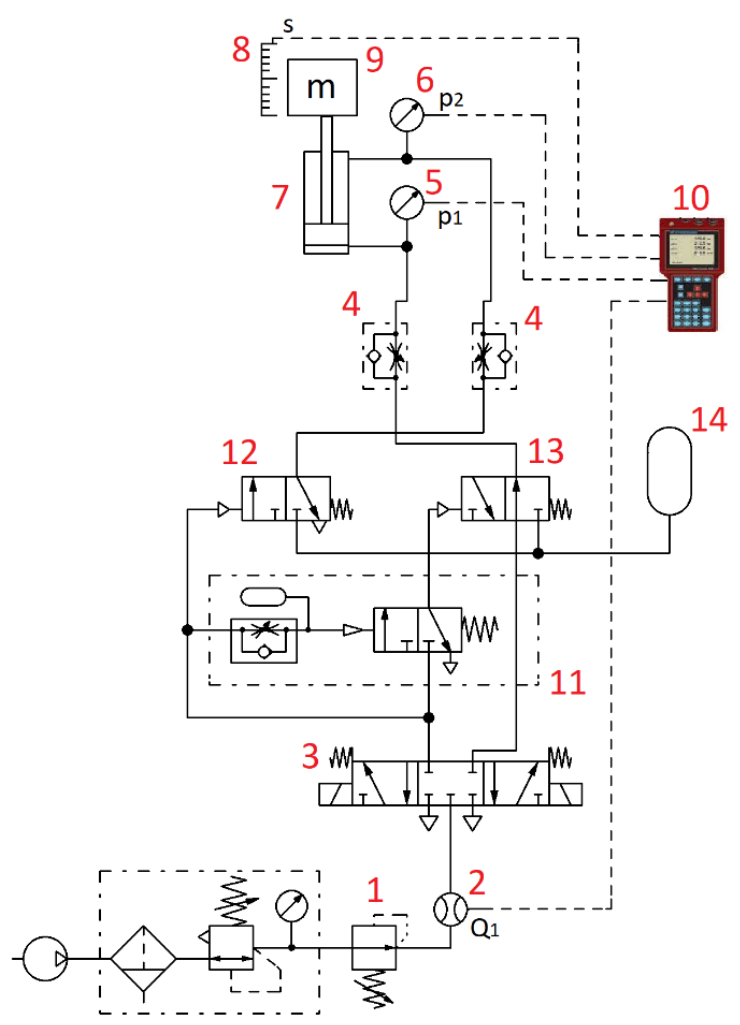

Fig. 11. The scheme of measurement with reservoir to accumulated exhaust air

1 -reduction valve, 2 -flow meter, 3 -directional control valve, 4 -throttle and check valve, 5 - pressure $p_{1}$ sensor, 6 -, pressure $p_{2}$ sensor 7 - pneumatic cylinder (linear motor), 8 - position sensor, 9 - mass load, 10 - measuring equipment M5050, 11 - time delay valve normally closed, 12 - 3/2 directional control valve, pneumatic operated, normally closed, 13 - 3/2 directional control valve, pneumatic operated, normally open, 14 - air reservoir

The comparison of air consumption for this task is in Tab.5. The realization of measurement is in Fig. 12.

Tab. 5. Comparison of each method to determine consumption of compressed air for measurement with air reservoir

\begin{tabular}{|c|c|c|}
\hline Method & $\begin{array}{c}\text { Working } \\
\text { pressure } \\
0.3 \mathrm{MPa} \\
{\left[\mathrm{dm}^{3}\right]}\end{array}$ & $\begin{array}{c}\text { Working } \\
\text { pressure } \\
0.4 \mathrm{MPa} \\
{\left[\mathrm{dm}^{3}\right]}\end{array}$ \\
\hline Flowmeter display & 2.6 & 3.2 \\
\hline Area under the curve & 2.8 & 3.312 \\
\hline Classic formula & 2.489 & 3.101 \\
\hline SMC formula & 3.474 & 4.343 \\
\hline
\end{tabular}



Fig. 12. The realization of measurement with reservoir to accumulated exhaust air
1 -reduction valve, 2 -flow meter, 3 -directional control valve, 4 -throttle and check valve, 5 - pressure $p_{1}$ sensor, $6-$, pressure $p_{2}$ sensor 7 - pneumatic cylinder (linear motor), 8 - position sensor, 9 - mass load, 10 - measuring equipment M5050, 11 - time delay valve normally closed, 12 - 3/2 directional control valve, pneumatic operated, normally closed, 13 - 3/2 directional control valve, pneumatic operated, normally open, 14 -air reservoir, 15 - pressure sensor

The measured data are shown in Fig.13 and Fig.14.

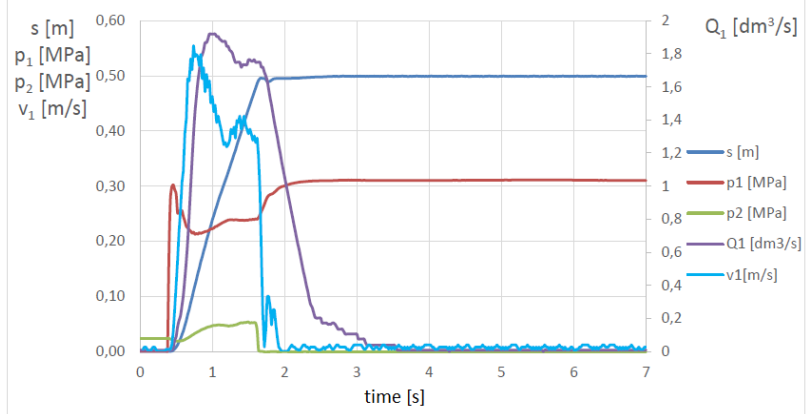

Fig.13. Graph of measured data for extension of piston rod, task with reservoir, for working pressure $0.3 \mathrm{MPa}$

$s$ - position of piston rod, $p_{1}$ - pressure on piston side, $p_{2}-$ pressure on piston rod side, $Q_{1}-$ flow rate, $v_{1}$-velocity of piston rod

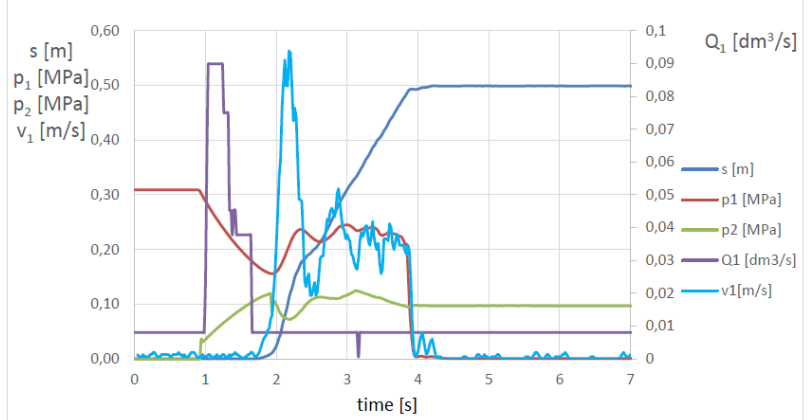

Fig.14. Graph of measured data for extension of piston rod, task with reservoir, for working pressure $0.3 \mathrm{MPa}$

\section{Conclusion}

For the evaluation and comparison of the individual tasks was used method of calculating the area under the curve (based on the measured data) and in consumption of compressed is included also the dead volume in pneumatic system. Measurements have shown that each of the tasks investigated leads to air savings. Comparison of individual tasks as the dependence of compressed air consumption on the number of cycles is shown in the Fig. 15 for workinkg pressure $0.3 \mathrm{MPa}$ and Fig.16 for working pressure $0.4 \mathrm{MPa}$.

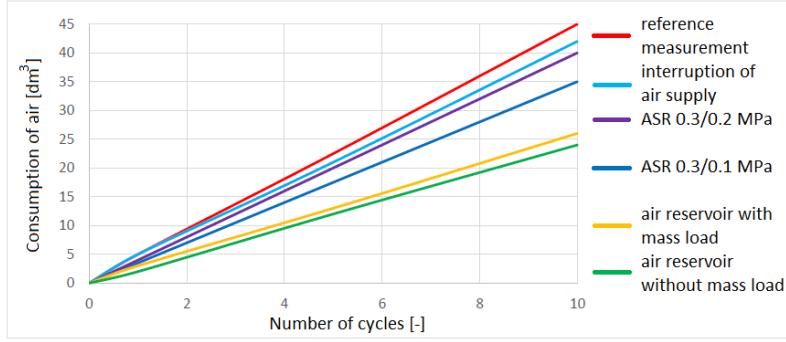

Fig. 15. Graph of consumption of compressed air for working pressure $0.3 \mathrm{MPa}$ 


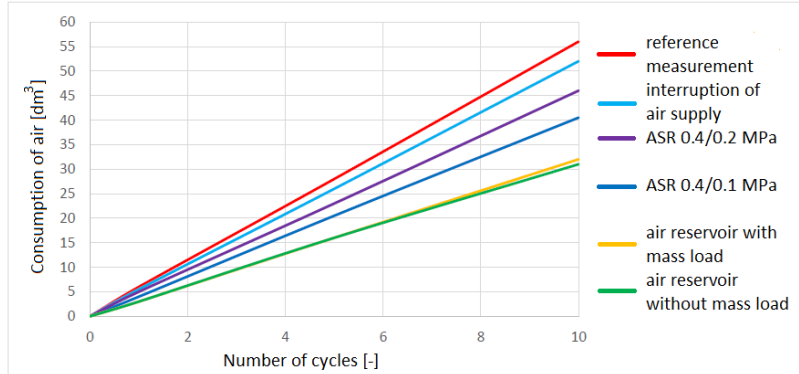

Fig. 16. Graph of consumption of compressed air for working pressure $0.4 \mathrm{MPa}$

The highest savings have been achieved for task with reservoir to accumulated exhaust air. This reservoir on output of pneumatic cylinder act as a pneumatic spring. Certainly we would find a lot of applications where this method could be used. On the other hand, the lowest savings have reached in task with directional control valve with closed middle position, whose savings with the increasing working pressure even drops. This is due to the fact that, after switching the valve to the middle position approximately the same pressure is closed in circuit behind the valve (both for working pressure $0.3 \mathrm{MPa}$ and $0.4 \mathrm{MPa}$. This closed pressure ensures savings, which means that with the increasing working pressure in the system the savings for this method will decrease.

Tab. 5. Energy savings for measured tasks, working pressure

\begin{tabular}{|c|c|c|c|}
\hline & $\begin{array}{c}\text { Consumption } \\
\text { for 1 cycle } \\
{\left[\mathrm{dm}^{3}\right]}\end{array}$ & $\begin{array}{c}\text { Energy } \\
\text { savings } \\
{[\%]}\end{array}$ & $\begin{array}{c}\text { Savings } \\
\text { for one } \\
\text { year } \\
{[\mathrm{EUR}]}\end{array}$ \\
\hline $\begin{array}{c}\text { Reference } \\
\text { measurement }\end{array}$ & 4.821 & 12 & 24.95 \\
\hline $\begin{array}{c}\text { Interruption } \\
\text { of air supply }\end{array}$ & 4.244 & 23.9 & 49.68 \\
\hline ASR 0.3/0.1 & 3.671 & 12.9 & 26.92 \\
\hline ASR 0.3/0.2 & 4.198 & 41.9 & 87.31 \\
\hline $\begin{array}{c}\text { Air reservoir } \\
\text { with mass } \\
\text { load }\end{array}$ & 2.8 & & \\
\hline
\end{tabular}

Tab. 6. Energy savings for measured tasks, working pressure

\begin{tabular}{|c|c|c|c|}
\hline & $\begin{array}{c}\text { Consumption } \\
\text { for 1 cycle } \\
{\left[\mathrm{dm}^{3}\right]}\end{array}$ & $\begin{array}{c}\text { Energy } \\
\text { savings } \\
{[\%]}\end{array}$ & $\begin{array}{c}\text { Savings } \\
\text { for one } \\
\text { year } \\
{[\text { EUR] }}\end{array}$ \\
\hline $\begin{array}{c}\text { Reference } \\
\text { measurement }\end{array}$ & 5.825 & 7.4 & 18.76 \\
\hline $\begin{array}{c}\text { Interruption } \\
\text { of air supply }\end{array}$ & 5.417 & 27.8 & 70.24 \\
\hline ASR 0.3/0.1 & 4.226 & 17.8 & 44.95 \\
\hline ASR 0.3/0.2 & 4.811 & 43.4 & 109.69 \\
\hline $\begin{array}{c}\text { Air reservoir } \\
\text { with mass } \\
\text { load }\end{array}$ & 3.312 & & \\
\hline
\end{tabular}

For all other measured tasks, it can be assumed that savings will also increase with increasing working pressure. Standard working pressure in pneumatic mechanisms is $0.6 \mathrm{MPa}$. The measured pressures $0.3 \mathrm{MPa}$ and $0.4 \mathrm{MPa}$ have been selected with respect to the laboratory conditions.

Tables 5 and 6 show the compressed for individual working pressures, energy savings comparison with reference measurement in \%. The table below also shows a financial savings when using the given method. For one year savings, 6000 hours of operation were considered. With price $0.015 E U R$ for $1 \mathrm{~m}_{N}^{3}$. For calculation of consumption is also important the time of one cycle. From measured data was selected 8 working cycles per minute. These savings are for one linear motor (and relatively low working pressure), in production lines are often tens or hundreds of pneumatic motors.

This work was supported by the grant SGS „Modeling and Experimental Verification of Dynamic Phenomena in Fluid and Vacuum Systems" SP2018/157.

This work was supported by the European Regional Development Fund in the Research Centre of Advanced Mechatronic Systems project, project number CZ.02.1.01/0.0/0.0/16_019/0000867 within the Operational Programme Research, Development and Education.

\section{References}

1. J. Kopáček, Pneumatické mechanismy (1998)

2. SMC Pneumatic, Inc., Basic Pneumatics, (1997)

3. FESTO Energy Saving online, https://www.festo.com/net/SupportPortal/Files/1742 3/555662_en.pdf

4. SMC, Air Saving Valve, online, https://www.smc.eu/portal_ssl/NEW EBP/13\%29F1 ow Control Equipment $/ 13.13 \% 29$ Air Saving Valv e/a\%29ASR_ASQ/ASR-ASQ_EU.pdf

5. L. Dvořák, K. Fojtášek, Pressure Regulators as Valves for Saving Compressed Air and their Influence on System Dynamics, EPJ Web of Conferences, Volume 92 (2015)

6. W. Gauchel, Fluidtechnik für den Maschinen- und Anlagenbau. O + P. (2006)

7. A. Dorazil, Reduction the Consumption of Compressed Air in Drives, Magister Thesis, (2018) 